\title{
Night Shift and its Impact upon the Quality of Life of Nurses Working at the Teaching Hospitals of the Medical City Complex in Baghdad City, Iraq
}

\section{Maan Hameed Ibrahim Al-Ameri*}

Psychiatric Mental Health Nursing Department, College of Nursing/ University of Baghdad' Iraq

*Corresponding author: Al-Ameri MHI, Assistant Professor, Psychiatric Mental Health Nursing Department, College of Nursing, University of Baghdad, Iraq, Tel: 981333238053; E-mail: dr.m.alameri@conursing.uobaghdad.edu.iq

Received date: April 19, 2017; Accepted date: July 17, 2017; Published date: July 25, 2017

Copyright: (c) 2017 Al-Ameri MHI. This is an open-access article distributed under the terms of the Creative Commons Attribution License, which permits unrestricted use, distribution, and reproduction in any medium, provided the original author and source are credited.

\section{Abstract}

Background: Nurses are key players in health care delivery, with night shift nurses having a special role in the provision of this health care. Night shift nurses are responsible for patient care with little support in a difficult working environment; under conditions of fatigue and other hardships directly related to working at night.

Objective: The present study aims to find out the impact of night shift on nurses quality of life; and to find out any relationship between the quality of life and some demographic characteristics such as age, gender, marital status, level of education and duration of career.

Methodology: A descriptive study was carried out to assess the nurses' quality of life. The nurses who work at Teaching hospitals of Medical City Complex were recruited from the 21st of February to 15th of July 2015. A nonprobability sample of 70 night shift nurses was selected. The investigator constructed the questionnaire for purpose of the study. This questionnaire consisted of two parts; some demographic characteristics of those nurses and a scale which assess the levels of quality of night shift nurses. Data are analysed using descriptive statistics (frequencies and percentages) and Pearson Chi-Square as an inferential statistical analysis.

Results: The study results revealed that the majority of study participants were young and married. About quarter of the number of the nurses have duration of career of five years and less. More than half of nurses had very weak and weak quality of life. Mid-aged nurses had lower levels of quality of life. The results showed that the male nurses had higher levels of quality of life than female nurses did and the married nurses are more likely to have lower levels of quality of life than unmarried did. Finally, there was a significant relationship between levels of quality of life and gender and age.

Recommendation: The study recommends that it should provide adequate off-duty hours to let an uninterrupted sleep cycle of at least $8 \mathrm{~h}$ a day, which may affect nurses' daily life at home. It should use permanent shift assignments, which may diminish tiredness effects, instead of rotating shift duties.

Keywords: Night shift; Impact; Quality; Life; Nurses; Medical; Hospitals

\section{Background}

The term shift work is defined as an arrangement of working hours that uses two or more teams (shifts) of workers, in order to extend the hours of operation of the work environment beyond that of the conventional office hours [1]. Nursing is considered as a stressful occupation [2-4]. Stress has an implication for health and the satisfaction level of the Nurses involved which eventually has an impact on the quality of care for the patients they attend to [5]. The night-shift nurses has rapidly increased worldwide over the last decades and nurses work long-hour night shift have become under conditions of intense stress. In addition, they often suffer from excessive workloads, stress, minimal social support and low quality of life [6]. Long-term night and shift work in nurses becoming more pessimistic and less vicarious as their training progresses, and might be associated with many health-related problems like fatigue, sleep problems, anxiety and difficulties in maintaining regular lifestyles [7].
Research in night shift has identified a number of stressors depending on the area of specialty. However, some common stressors in these specialties include poor working relationship between nurses and other health team members, demanding communication and relationship with patients' relatives, emergency cases, high workload, understaffed and lack of support or feedback from their seniors [8,9]. Working in night shifts creates difficulties in family life and tends to restrict nurses' social and leisure activities [10]. Particularly, working at night, either on permanent or rotating shifts, often produces discordance with the spouse's working hours and free time [11]. Nurses in $12 \mathrm{~h}$ shifts reported less social and domestic disruption than workers in $8 \mathrm{~h}$ shifts $[12,13]$. Numerous studies have shown high amounts of psychological distress in nurses and other healthcare professionals working in various situations [14]. Night shift causes an imbalance between desired lifestyle and work, women have a major role to play in the domestic life and they compromise their sleep to undertake the domestic chores such as care to their children and family chores. To find out whether night shift affects the social aspect of nurses or not $60 \%$ of respondents stated that their social life is sometimes affected, $33 \%$ stated that always their social life is affected that is mean $93 \%$ of 
Page 2 of 5

the nurses are affected and 7\% not affected. The aspect of social life involves nurses' families, work relationships and other social groups [6].

\section{Objective}

The present study aimed to find out the impact of night shift on nurses quality of life; and to find out any relationship between the quality of life and some demographic characteristics such as age, gender, marital status, level of education, and duration of career.

\section{Methodology}

Descriptive design with application of assessment approach study was used from 21st of February to 15th of July 2015. A non-probability sample of 70 nurses were recruited at five hospitals of the Medical City Complex which are Baghdad Teaching Hospital, Ghazi al-Hariri Hospital for surgery, Private Nursing Home, Liver and Digestive System Diseases Hospital, and Teaching Hospital for Burns; 20 nurses; 20 nurses; 15 nurses; 10 nurses; and 5 nurses respectively. A questionnaire was constructed and designed to meet the objectives of present study. This questionnaire consisted of two parts: firstly, demographic characteristics of the nurses jointed in the study such as gender, age, marital status, level of education, and duration of career. Secondly a scale was used to assess the levels of quality of life of nurses participating in the study, this scale The Quality of Life (WHOQOL)BREF [15] that includes five Domains: psychological domain: nine items; physical domain: eight items; spiritual and religious domain: three items; social domain: seven items; and environment and housing: eight items. This scale is self-administered. The total items scores was measured, scored and finally rated on 4-level rating scale [12]. Four levels were determined by applying quartile descriptive analysis. Very weak level is with cut-off point ranged from 57 to 66; weak level is with cut-off point ranged from 67 to 71; intermediate level is with cut-off point ranged from 72 to 76 ; good level is with cut-off point ranged from 77 to 105 . Data were analysed by applying the statistical package for the social sciences (SPASS) for windows, version 19; the descriptive statistical measures of frequency, percent, distribution tables and quartiles; and inferential data analysis: this approach was performed through the application of the-correlation coefficient; Pearson ChiSquare.

\section{Results}

The results of demographic characters of the students, distribution of sample, distribution in level of QoL regarding to age, gender, marital status, education level and duration of career can be shown in the below tables (Tables 1-8).

\begin{tabular}{|c|c|c|c|c|c|}
\hline \multicolumn{3}{|c|}{ Age } & \multicolumn{3}{c|}{ Marital Status } \\
\hline & $\mathbf{f}$ & $\%$ & Status & $\mathbf{f}$ & $\%$ \\
\hline $20-29$ & 22 & $31.40 \%$ & Unmarried & 27 & $38.60 \%$ \\
\hline
\end{tabular}

\begin{tabular}{|c|c|c|c|c|c|}
\hline $30-39$ & 32 & $45.70 \%$ & Married & 41 & $58.60 \%$ \\
\hline $40-49$ & 11 & $15.70 \%$ & Divorced & 1 & $1.40 \%$ \\
\hline$\geq 50$ & 5 & $7.10 \%$ & Widowed & 1 & $1.40 \%$ \\
\hline Total & 70 & $100.00 \%$ & Total & 70 & $100.00 \%$ \\
\hline \multicolumn{3}{|c|}{ Gender } & \multicolumn{3}{|c|}{ Levels of Education } \\
\hline & f & $\%$ & & f & $\%$ \\
\hline Female & 47 & $67.10 \%$ & Secondary & 24 & $34.30 \%$ \\
\hline Male & 23 & $32.90 \%$ & Institute & 38 & $54.30 \%$ \\
\hline \multirow[t]{2}{*}{ Total } & 70 & $100.00 \%$ & College & 8 & $11.40 \%$ \\
\hline & & & Total & 70 & $100.00 \%$ \\
\hline \multicolumn{6}{|c|}{ Duration of Career } \\
\hline & & \multicolumn{2}{|c|}{$f$} & \multicolumn{2}{|r|}{$\%$} \\
\hline \multicolumn{2}{|l|}{$\leq 5$} & \multicolumn{2}{|c|}{26} & \multicolumn{2}{|c|}{$37.10 \%$} \\
\hline \multicolumn{2}{|l|}{ 06-Oct } & \multicolumn{2}{|c|}{16} & \multicolumn{2}{|c|}{$22.90 \%$} \\
\hline \multicolumn{2}{|c|}{ Nov-15 } & \multicolumn{2}{|c|}{15} & \multicolumn{2}{|c|}{$21.40 \%$} \\
\hline \multicolumn{2}{|l|}{$16-20$} & \multicolumn{2}{|c|}{4} & \multicolumn{2}{|c|}{$5.70 \%$} \\
\hline \multicolumn{2}{|l|}{$\geq 21$} & \multicolumn{2}{|c|}{9} & \multicolumn{2}{|c|}{$12.90 \%$} \\
\hline \multicolumn{2}{|l|}{ Total } & \multicolumn{2}{|c|}{70} & \multicolumn{2}{|r|}{$100 \%$} \\
\hline
\end{tabular}

Table 1: Demographic characteristics of the students participated in the study, Table 1 shows that the highest percentage of the sample age were from $(22-23)$ years old $(28.7 \%), 67.3 \%$ were female, $26.0 \%$ were from fourth stage, $66.0 \%$ reside in Baghdad, and $81.7 \%$ were unmarried.

\begin{tabular}{|l|l|l|l|}
\hline & & $\mathbf{f}$ & $\%$ \\
\hline \multirow{4}{*}{ Levels of Quality } & Very Weak & 15 & $21.40 \%$ \\
\cline { 2 - 4 } & Weak & 21 & $30.00 \%$ \\
\cline { 2 - 4 } & Intermediate & 18 & $25.70 \%$ \\
\cline { 2 - 4 } & Good & 16 & $22.90 \%$ \\
\cline { 2 - 4 } & Total & 70 & $100.00 \%$ \\
\hline
\end{tabular}

Table 2: Distribution of the sample according to the Levels of quality of life of nurses, 57-66: Very weak; 67-71: Weak; 72-76: Intermediate; and 77-105: Good, The results indicate that regarding the levels of quality of life, about half of them (50.4\%) have very weak and weak levels and only $22.9 \%$ are with good level of quality life.

\begin{tabular}{|c|c|c|c|c|c|c|c|}
\hline & & & \multicolumn{5}{|c|}{ Level of QoL } \\
\hline & & & Very weak & Weak & Intermediate & Good & Total \\
\hline Age & $20-29$ & $f$ & 2 & 7 & 5 & 8 & 22 \\
\hline
\end{tabular}


Citation: Al-Ameri MHI (2017) Night Shift and its Impact upon the Quality of Life of Nurses Working at the Teaching Hospitals of the Medical City

\begin{tabular}{|c|c|c|c|c|c|c|c|}
\hline & & $\%$ & $2.90 \%$ & $10.00 \%$ & $7.10 \%$ & $11.40 \%$ & $31.40 \%$ \\
\hline & & $f$ & 7 & 10 & 10 & 5 & 32 \\
\hline & 30-39 & $\%$ & $10.00 \%$ & $14.30 \%$ & $14.30 \%$ & $7.10 \%$ & $45.70 \%$ \\
\hline & & f & 4 & 4 & 3 & 0 & 11 \\
\hline & $40-49$ & $\%$ & $5.70 \%$ & $5.70 \%$ & $4.30 \%$ & $0.00 \%$ & $15.70 \%$ \\
\hline & & f & 2 & 0 & 0 & 3 & 5 \\
\hline & $\geq 50$ & $\%$ & $2.90 \%$ & $0.00 \%$ & $0.00 \%$ & $4.30 \%$ & $7.10 \%$ \\
\hline & & $f$ & 15 & 21 & 18 & 16 & 70 \\
\hline Total & & $\%$ & $21.40 \%$ & $30.00 \%$ & $25.70 \%$ & $22.90 \%$ & $100.00 \%$ \\
\hline
\end{tabular}

Table 3: Distribution in the levels of quality of life regarding to age of nurses, Table 3 shows that the highest level of QoL is within the age group of (30-39); and the lowest level is within age group $(\geq 50)$.

\begin{tabular}{|c|c|c|c|c|c|c|c|}
\hline & & & \multicolumn{5}{|c|}{ Level of QoL } \\
\hline & & & Very Weak & Weak & Intermediate & Good & Total \\
\hline \multirow[b]{4}{*}{ Gender } & Male & f & 8 & 18 & 15 & 6 & 47 \\
\hline & & $\%$ & $11.40 \%$ & $25.70 \%$ & $21.40 \%$ & $8.60 \%$ & $67.10 \%$ \\
\hline & Female & $f$ & 7 & 3 & 3 & 10 & 23 \\
\hline & & $\%$ & $10.00 \%$ & $4.30 \%$ & $4.30 \%$ & $14.30 \%$ & $32.90 \%$ \\
\hline \multirow[b]{2}{*}{ Total } & & $f$ & 15 & 21 & 18 & 16 & 70 \\
\hline & & $\%$ & $21.40 \%$ & $30.00 \%$ & $25.70 \%$ & $22.90 \%$ & $100.00 \%$ \\
\hline
\end{tabular}

Table 4: Distribution in the levels of quality of life regarding to gender of nurses, Table 4 indicates that $25.7 \%$ of the male has weak level and only 8.6\% have good level of QoL.

\begin{tabular}{|c|c|c|c|c|c|c|c|}
\hline & & & \multicolumn{5}{|c|}{ Level of QoL } \\
\hline & & & Very Weak & Weak & Intermediate & Good & Total \\
\hline & \multirow[b]{2}{*}{ Unmarried } & $f$ & 4 & 7 & 10 & 6 & 27 \\
\hline & & $\%$ & $5.70 \%$ & $10.00 \%$ & $14.30 \%$ & $8.60 \%$ & $38.60 \%$ \\
\hline & \multirow[b]{2}{*}{ Married } & $f$ & 10 & 14 & 8 & 9 & 41 \\
\hline & & $\%$ & $14.30 \%$ & $20.00 \%$ & $11.40 \%$ & $12.90 \%$ & $58.60 \%$ \\
\hline & & $f$ & 1 & 0 & 0 & 0 & 1 \\
\hline & Divorced & $\%$ & $1.40 \%$ & $0.00 \%$ & $0.00 \%$ & $0.00 \%$ & $1.40 \%$ \\
\hline \multirow[b]{2}{*}{ Marital Status } & \multirow[b]{2}{*}{ Widowed } & $f$ & 0 & 0 & 0 & 1 & 1 \\
\hline & & $\%$ & $0.00 \%$ & $0.00 \%$ & $0.00 \%$ & $1.40 \%$ & $1.40 \%$ \\
\hline \multirow[b]{2}{*}{ Total } & & f & 15 & 21 & 18 & 16 & 70 \\
\hline & & $\%$ & $21.40 \%$ & $30.00 \%$ & $25.70 \%$ & $22.90 \%$ & $100.00 \%$ \\
\hline
\end{tabular}

Table 5: Distribution in the levels of quality of life regarding to marital status of nurses, Table 5 shows that two third of married nurses have weak and very weak level of QoL and only 8.6\% have good level of QoL. 
Citation: Al-Ameri MHI (2017) Night Shift and its Impact upon the Quality of Life of Nurses Working at the Teaching Hospitals of the Medical City Complex in Baghdad City, Iraq. J Nurs Care 6: 414. doi:10.4172/2167-1168.1000414

Page 4 of 5

\begin{tabular}{|c|c|c|c|c|c|c|c|}
\hline & & & & & Levels of QoL & & \\
\hline & & & Very Weak & Weak & Intermediate & Good & Total \\
\hline \multirow{6}{*}{$\begin{array}{l}\text { Level of } \\
\text { Education }\end{array}$} & \multirow[b]{2}{*}{ Secondary } & $f$ & 6 & 5 & 4 & 9 & 24 \\
\hline & & $\%$ & $8.60 \%$ & $7.10 \%$ & $5.70 \%$ & $12.90 \%$ & $34.30 \%$ \\
\hline & \multirow[b]{2}{*}{ Institute } & $f$ & 7 & 15 & 10 & 6 & 38 \\
\hline & & $\%$ & $10.00 \%$ & $21.40 \%$ & $14.30 \%$ & $8.60 \%$ & $54.30 \%$ \\
\hline & \multirow[b]{2}{*}{ College } & $f$ & 2 & 1 & 4 & 1 & 8 \\
\hline & & $\%$ & $2.90 \%$ & $1.40 \%$ & $5.70 \%$ & $1.40 \%$ & $11.40 \%$ \\
\hline \multirow[b]{2}{*}{ Total } & & $f$ & 15 & 21 & 18 & 16 & 70 \\
\hline & & $\%$ & $21.40 \%$ & $30.00 \%$ & $25.70 \%$ & $22.90 \%$ & $100.00 \%$ \\
\hline
\end{tabular}

Table 6: Distribution in the levels of quality of life regarding to the levels of education of nurses, Table 6 reveals that most of institute level of education has weak and very weak levels of QoL (31.4\%); and only 8.6\% have good level of QoL.

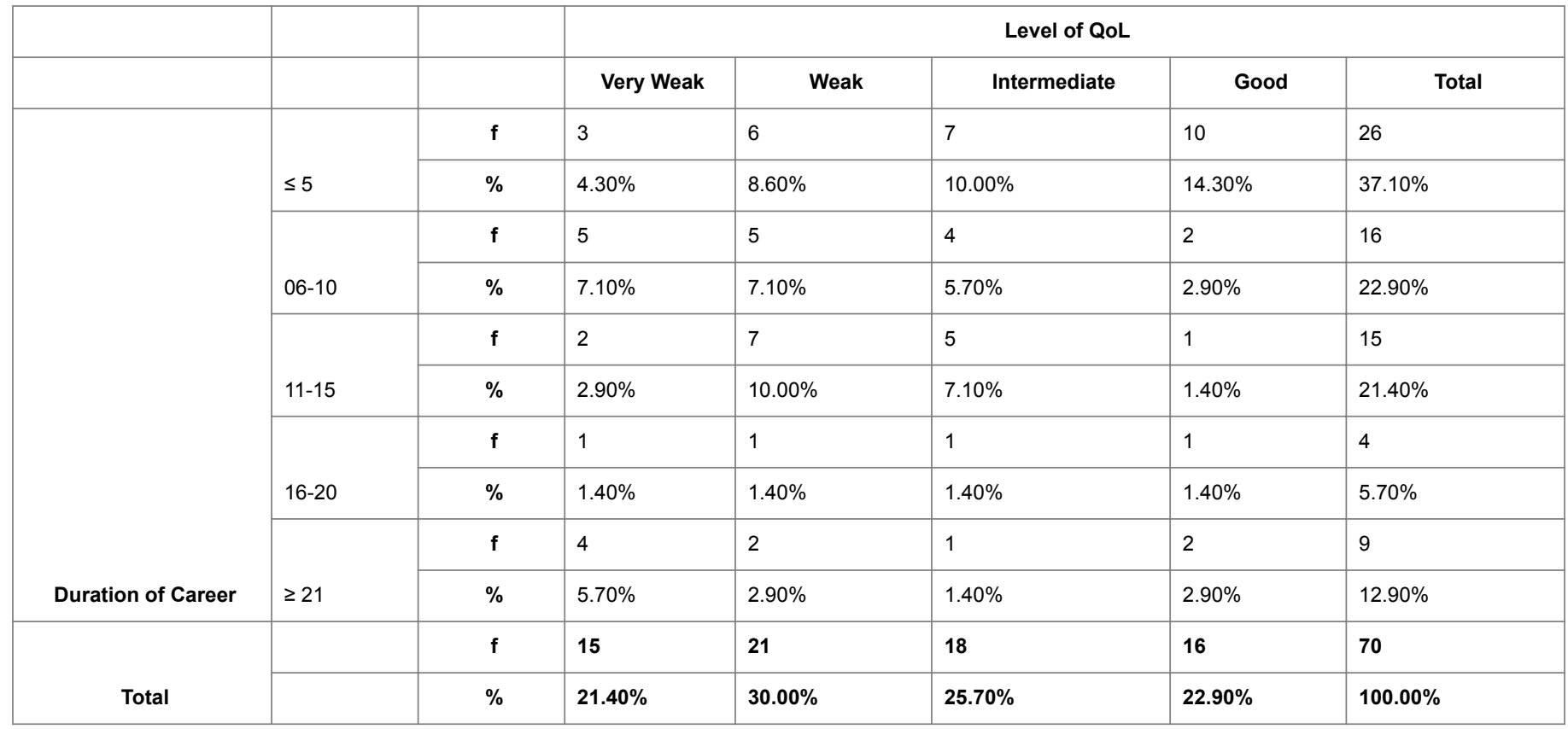

Table 7: Distribution in the levels of quality of life regarding to the duration of career of nurses, Table 7 shows that $14.3 \%$ of total nurses have a good level of quality of life within five years of career; and only 1.4\% have very weak level within career group of 16-20.

\begin{tabular}{|c|c|c|c|}
\hline $\begin{array}{l}\text { Demographic } \\
\text { characteristics }\end{array}$ & $\begin{array}{l}\text { Pearson Chi- } \\
\text { Square }\end{array}$ & & \\
\hline & $\mathbf{x}^{2}$ & df & Sig. \\
\hline Age & 14.98 & 3 & 0.05 \\
\hline Gender & 13.09 & 1 & 0.01 \\
\hline Marital Status & 10.12 & 3 & 0.34 \\
\hline Level of Education & 9.034 & 2 & 0.17 \\
\hline
\end{tabular}

\begin{tabular}{|l|l|l|l|}
\hline Duration of Career & 12.99 & 4 & 0.37 \\
\hline
\end{tabular}

Table 8: Association between demographic characteristics and levels of QoL, Table 8 indicates that there is significant relationship between age and level of QoL.

\section{Discussion and Conclusion}

The results of Table 1 show that the majority of nurses are young and mid-aged ( 20 to 40 years old), this result is supported by Al-Ameri and other studies [16-19] who confirmed that about 68.2 to $72.1 \%$ of their studies' samples were with age ranged between 19 to 39 years. About three quarters of the nurses participated in present study were 
male, this finding was supported by Al-Ameri [16] and Lee and Henderson [20] who found in their studies on psychiatric nurses that 68 to $72 \%$ of those nurses were male. These results could be due the difficulties in working during night shift so the male nurses are more suitable to work at night. Concerning the levels of education of the nurses, the results show that about half of the nurses have diploma in nursing which means two years after secondary school. This result is supported by Al-Ameri [16] but this result is not supported by American and European studies because the standard of level of education for nurses is Bachelor in nursing level [21-23]. More than half of the nurses were married; this situation is considered traditional commitment in Iraq to marry at early years of age, in addition the majority of the participants is 20-39 years old so it is usual to find this high percentage of married nurses [16]. The majority of the sample $(81.4 \%)$ was with more than five years and less than 15 years of career. These different periods of career are normal due to different ages and different levels of education. About half of the nurses took place in the present study have weak and very weak quality of life, that indicates a bad impact of night shift upon the physical, psychological and social status of a large number of nurses working at night shift [2]. The female nurse are under more burdens of night shift than male nurse are. Moreover, the more the nurse is older the less quality of life has [24]. The married nurses (whether male or female) are more likely to have weaker level of quality of life, this might be due to the difficulties of everyday life events which add more burdens on the nurses in addition to night shift burdens [25]. Those who have ten years of career and less are more likely to have weak and very weak levels of quality of life; this is could be because they have not adjusted very well with night shift work.

\section{Recommendation}

The present study recommends that it should provide adequate offduty hours to let an uninterrupted sleep cycle of at least eight hour a day, which may affect nurses' daily life at home. It should use permanent shift assignments, which may diminish tiredness effects, instead of rotating shift duties. Encourage the nurses to join the special sessions for coping and stress management to lessen and prevent the work-related stress.

\section{References}

1. Knutsson A, Alfredsson L, Karlsson B (2012) Breast cancer among shift workers: Results of the WOLF longitudinal cohort study. Scand J Work Env Health 39: 170-177.

2. Vitale SA, Varrone-Ganesh J, Vu M (2015) Nurses working the night shift: Impact on home, family and social life. J Nurs Educ Pract 5: 70-78.

3. Martin R (2011) Differences in health and well-being of night shift nurses versus day shift nurses [dissertation]. Northern Kentucky University, p: 38.

4. Bonet-Porqueras R, Moline-Pallares A, Olona-Cabases M (2009) The night shift: A risk factor for health and quality of life in nursing staff. Enferm Clin 19: 76-82.
5. Silva-Costa A, Rotenberg L, Griep R (2011) Relationship between sleeping on the night shift and recovery from work among nursing workers: The influence of domestic work. J Adv Nurs 67: 972-981.

6. Buyukhatipoglu H, Kirhan I, Vural M (2010) Oxidative stress increased in healthcare workers working $24 \mathrm{~h}$ on-call shifts. Am J Med Sci 340:462-467.

7. Marion da Silva R., Beck C, Guido L (2009) Night shift pros and cons in nursing: qualitative study. Online Brazilian Journal of Nursing 8.

8. Barrientos LA, Suazo SV (2007) Quality of life associated factors in Chilenas hospitals nurses. Rev Latino-Am Enfermagem 15: 480-486.

9. Suzuki K, Ohida T, Kaneita Y, Yokoyama E, Miyake T, et al. (2004) Mental health status, shift work and occupational accidents among hospital nurses in Japan. J Occup Health 46: 448-454.

10. Totterdell P, Spelten E, Pokorski J (1995) The effects of night work on psychological changes during the menstrual cycle. J Adv Nurs 21: 996-1005.

11. Persson M, Martensson J (2006) Situations influencing habits in diet and exercises among nurses working night shift. J Nurs Manag 14: 414-423.

12. Yuan SC, Chou MC, Chen CJ, Lin YJ, Chen MC, et al. (2011) Influences of-shift work on fatigue among nurses. J Nurs Manag 19: 339-345.

13. Shields M (2002) Shift work and health. Health Rep 13: 11-33.

14. Akerstedt T, Kecklund G, Johansson SE (2004) Shift work and mortality. Chronobiol Int 21: 1055-1061.

15. World Health Organization Quality of Life (WHOQOL) Group (1995) World Health Organization quality of life assessment (WHOQOL): Position paper from the World Health Organization. Soc Sci Med 41: 1403-1409.

16. Al-Ameri MHI (2014) Sources of work-related Stress among Nurses Working at Psychiatric Wards in Baghdad City Hospitals. Iraqi National Journal of Nursing Specialties 27: 51-58.

17. Santos SR, Carroll CA, Cox KS (2003) Baby boomer nurses bearing the burden of care: a four-site study of stress, strain, and coping for inpatient registered nurses. J Nurs Adm 33: 243-250.

18. Folkard S, Tucker P (2003) Shift work, safety and productivity. Occup Med (Lond) 53: 95-101.

19. Geiger-Brown J, Trinkoff A (2010) Is it time to pull the plug on $12 \mathrm{~h}$ shifts? Part 1. J Nurs Adm 40: 100-102.

20. Lee V, Henderson MC (1996) Occupational stress and organizational commitment in nurse administrators. J Nurs Adm 26: 21-28.

21. Gray P (2000) Mental health in the workplace: Tackling the effects of stress. Mental Health Foundation, London.

22. Chang YS, Wu YH (2011) Impairment of perceptual and motor abilities at the end of a night shift is greater in nurses working fast rotating shifts. Sleep Med 12: 866-869.

23. Schernhammer ES, Kroenke CH, Laden F, Hankinson SE (2006) Night work and risk of breast cancer. Epidemiology 17: 108-111.

24. Tepas DI, Barnes-Farrel JL (2004) The impact of night work on subjective reports of well-being: An exploratory study of heath care workers from five nations. Rev Saude Publica 38: 26-31.

25. Isikhan V, Comez T, Danis MZ (2004) Job stress and coping strategies in health care professionals working with cancer patients. Eur J Oncol Nurs 8: 234-244. 